\title{
Erratum: Depolarization of Electronic Spin Qubits Confined in Semiconductor Quantum Dots [Phys. Rev. X 8, 041050 (2018)]
}

Dan Cogan $\odot$, Oded Kenneth, Netanel H. Lindner, Giora Peniakov, Caspar Hopfmann, Dan Dalacu, Philip J. Poole, Pawel Hawrylak, and David Gershoni

(Q) (Received 23 December 2020; published 27 January 2021)

DOI: $10.1103 /$ PhysRevX.11.019901

Equation (A9) had a small typo. The coefficient of the second term in the brackets should be 12 instead of 2 . The correct equation is

$$
f_{3 / 2}(t)=\frac{3}{5}+\frac{2}{5}\left[1-12\left(\frac{\gamma_{Q} t}{\hbar}\right)^{2}+12\left(\frac{\gamma_{Q} t}{\hbar}\right)^{4}\right] e^{-3\left(\gamma_{Q} t / \hbar\right)^{2}}
$$

Published by the American Physical Society under the terms of the Creative Commons Attribution 4.0 International license. Further distribution of this work must maintain attribution to the author(s) and the published articles title, journal citation, and DOI. 